\title{
OCUPACIONES HUMANAS Y CAMBIO A LO LARGO DEL HOLOCENO EN ABRIGOS ROCOSOS DE LA PUNA DE SALTA, ARGENTINA: UNA PERSPECTIVA REGIONAL
}

\author{
HUMAN OCCUPATIONS AND CHANGE THROUGHOUT THE HOLOCENE \\ IN THE ROCKSHELTERS OF THE PUNA OF SALTA, ARGENTINA: \\ A REGIONAL PERSPECTIVE
}

Gabriel E.J. López ${ }^{1}$

\begin{abstract}
Este trabajo analiza y discute los procesos de cambio ocurridos a lo largo del Holoceno en el uso de fauna y en la tecnología lítica en dos abrigos rocosos de la puna de Salta, noroeste de Argentina. Con este objetivo se sintetiza y compara parte de la información arqueológica reunida hasta el momento en ambos sitios, Alero Cuevas y Abrigo Pozo Cavado, ubicados en las cuencas de Pastos Grandes y Pocitos, respectivamente. Ambos sitios presentan largas secuencias de ocupación humana a lo largo del Holoceno. El marco teórico es ecológico evolutivo y la metodología de análisis se centra en estudios zooarqueológicos y líticos. Los resultados indican que los cambios económicos y tecnológicos más notables comienzan hacia finales del Holoceno medio y se extienden durante el Holoceno tardío con indicadores de variabilidad regional. Más generalmente, estos sitios aportan nueva evidencia arqueológica para discutir los procesos de cambio ocurridos a lo largo del Holoceno en los Andes centro sur.
\end{abstract}

Palabras claves: puna, abrigos, cambio cultural, zooarqueología, tecnología lítica.

This paper analyzes and discusses the processes of change that occurred throughout the Holocene in the use of fauna and lithic technology in two rock shelters in the Puna of Salta, Northwest of Argentina. Synthesized archaeological data is compared from both sites considered here, Alero Cuevas and Abrigo Pozo Cavado, located in the basins of Pastos Grandes and Pocitos respectively. Both sites have long sequences of human occupation throughout the Holocene. The theoretical framework is ecological evolutionary and methodology draws from zooarchaeological and lithic studies. The results indicate the most significant economic and technological changes are evident from the end of the middle Holocene and continue during the late Holocene, while developing regional variation. In general, these sites provide new archaeological evidence allowing a deeper discussion of the processes of change that occurred during the Holocene in the South-Central Andes.

Key words: South-Central Andes Puna, ecological evolutionary, cultural change, zooarchaeology, lithic technology.

En la puna argentina, los abrigos rocosos proveen la mayor parte de la evidencia arqueológica de cambios en las ocupaciones humanas a lo largo del Holoceno. En general, esto se debe a la buena preservación de contextos arqueológicos en capa en estos sitios. La escasez general de cuevas y aleros en la puna y las ventajas de reparo que presentan para la ocupación humana, convertirían a muchos de estos sitios en lugares de uso persistente (Schlanger 1992). Este es el caso de dos sitios registrados en los últimos años en la puna de Salta, Noroeste argentino, que presentan largas secuencias de ocupación humana: Alero Cuevas y Abrigo Pozo Cavado (Figura 1).

El sitio Alero Cuevas se ubica en la cuenca de Pastos Grandes, a una altura de 4.400 msm y presenta una secuencia que abarca el Holoceno Temprano, Medio y Tardío (López 2009a). Por su parte, el Abrigo Pozo Cavado se ubica en la cuenca de Pocitos (a $60 \mathrm{~km}$ al oeste de Pastos Grandes) a una altura de $3.700 \mathrm{msm}$ y presenta ocupaciones entre el Holoceno Medio y el Holoceno Tardío (López 2012; López et al. 2012).

Este trabajo realiza una primera aproximación comparativa de la evidencia arqueológica en estos sitios con el fin de discutir los procesos de cambio en el uso humano de fauna y en la tecnología lítica a lo largo del Holoceno. Fundamentalmente, se hace hincapié en los cambios relacionados con la intensificación y domesticación de camélidos a partir de finales del Holoceno medio. En este sentido, desde una perspectiva regional amplia, los sitios

1 CONICET. Instituto de Arqueología, Universidad de Buenos Aires, Buenos Aires, Argentina. gabelope@ yahoo.com 


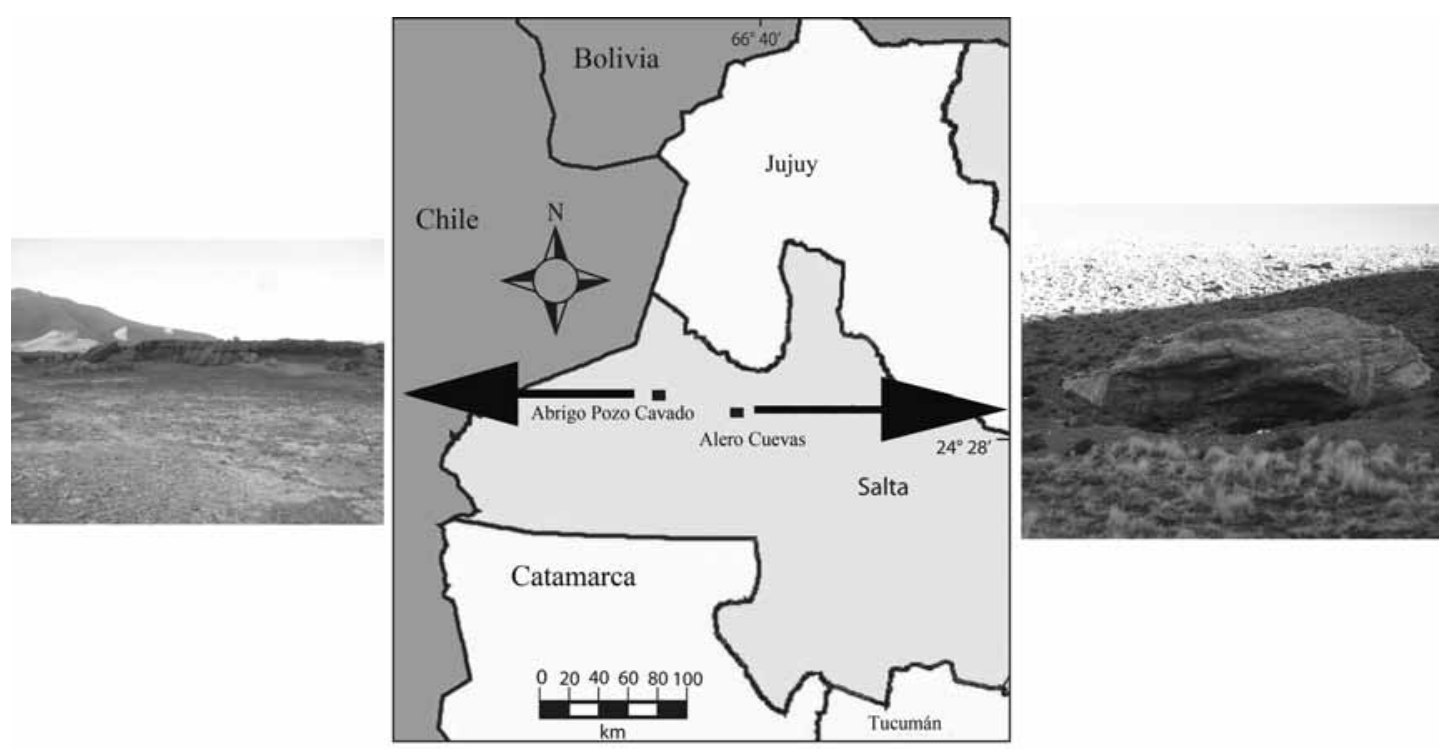

Figura 1. Ubicación de los sitios Alero Cuevas y Abrigo Pozo Cavado.

Location of the Alero Cuevas and Abrigo Pozo Cavado.

Alero Cuevas y Abrigo Pozo Cavado aportan nueva evidencia arqueológica para discutir los procesos de cambio en las cuencas de Pastos Grandes y Pocitos, y más generalmente, en los Andes centro sur.

\section{Marco Ambiental y Cronológico}

La cuenca de Pastos Grandes se ubica a una altura promedio superior a los $4.000 \mathrm{msm}$ y se conforma por las aguas de deshielo provenientes de los nevados en dirección norte, que desembocan en el salar del mismo nombre. Dentro de la cuenca pueden segmentarse sectores distintivos por sus características geomorfólogicas y ecológicas (López 2009b). Las quebradas presentan una productividad de recursos vegetales y animales mayor que otros sectores del área, especialmente a partir de la disponibilidad permanente de agua desde los nevados de Pastos Grandes (Figura 2A). En este sector se encuentra el sitio Alero Cuevas.

La cuenca de Pocitos se ubica al Oeste de Pastos Grandes, a una distancia de $60 \mathrm{~km}$. A diferencia de Pastos Grandes, la calidad global de este ambiente de mesoescala es menor en cuanto a disponibilidad de agua y recursos alimenticios (Figura 2B). Claramente es un ambiente de borde salar con escasos sectores de vegas o paleovegas y una baja calidad global para la instalación humana residencial. Sin embargo, en algunos sectores de este salar se evidencian formaciones rocosas que pudieron usarse por grupos humanos como refugio. Uno de ellos es el Abrigo Pozo Cavado.

Las diferencias ambientales de los sectores en los que se ubican el sitio Alero Cuevas y el Abrigo Pozo Cavado son importantes. A pesar de estas diferencias, ambos sitios presentan largas secuencias de ocupación humana, tal como lo demuestra la cronología absoluta (Tabla 1). Sin embargo, es importante señalar que Abrigo Pozo Cavado se encuentra en proceso de excavación para ampliar las muestras obtenidas hasta el momento, y especialmente aumentar la cantidad de fechados (actualmente hay $2 \mathrm{~m}^{2}$ excavados). En este sentido, no se descarta que con la ampliación de la excavación y la obtención de nueva cronología puedan registrarse ocupaciones en el Holoceno Temprano. Por el momento la cronología disponible y la evidencia arqueológica general permiten señalar ocupaciones humanas en el Holoceno Medio y Tardío.

Por su parte, en el sitio Alero Cuevas la excavación de $8 \mathrm{~m}^{2}$ permitió registrar ocupaciones en el Holoceno Temprano, Medio y Tardío.

En ambos sitios la estratigrafía presenta distintas capas con variaciones por el contenido orgánico y pedregoso, y por su textura y color. En la Figura 3 se observa la distribución de las capas en la estratigrafía de ambos sitios. La matriz general está compuesta por sedimento de limo que llega hasta 


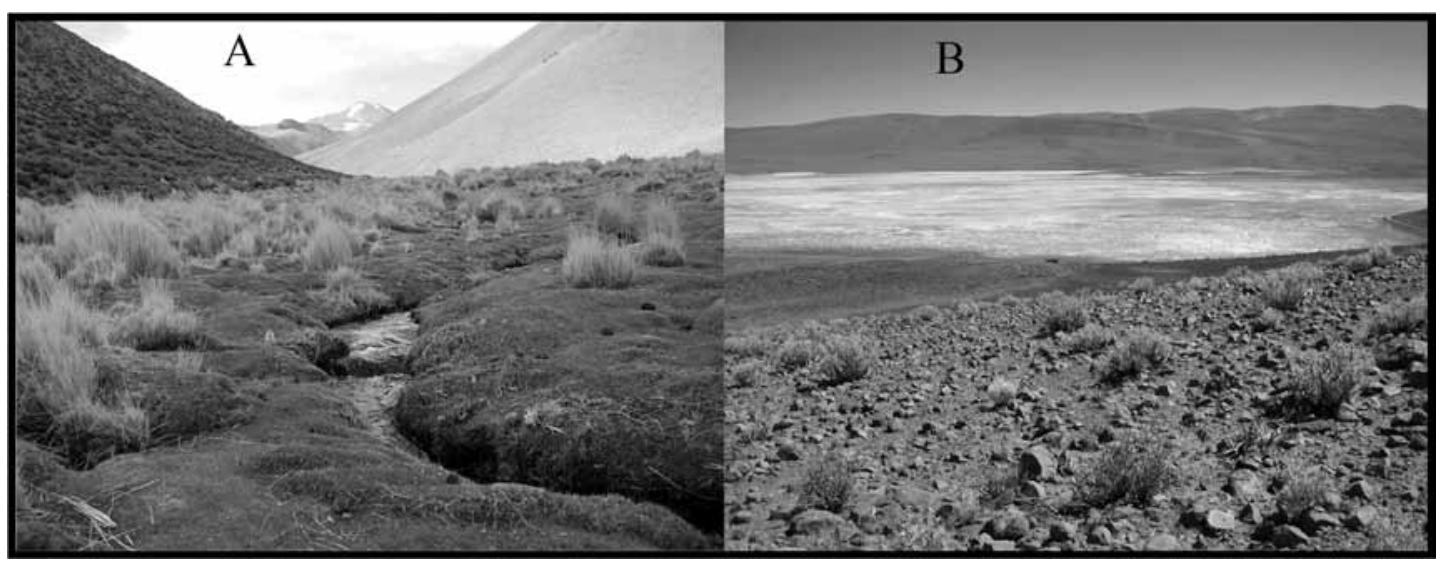

Figura 2. A. Quebrada en Pastos Grandes. B. Salar de Pocitos.

A. Gorge in Pastos Grandes. B. Pocitos Salt Flat.

B

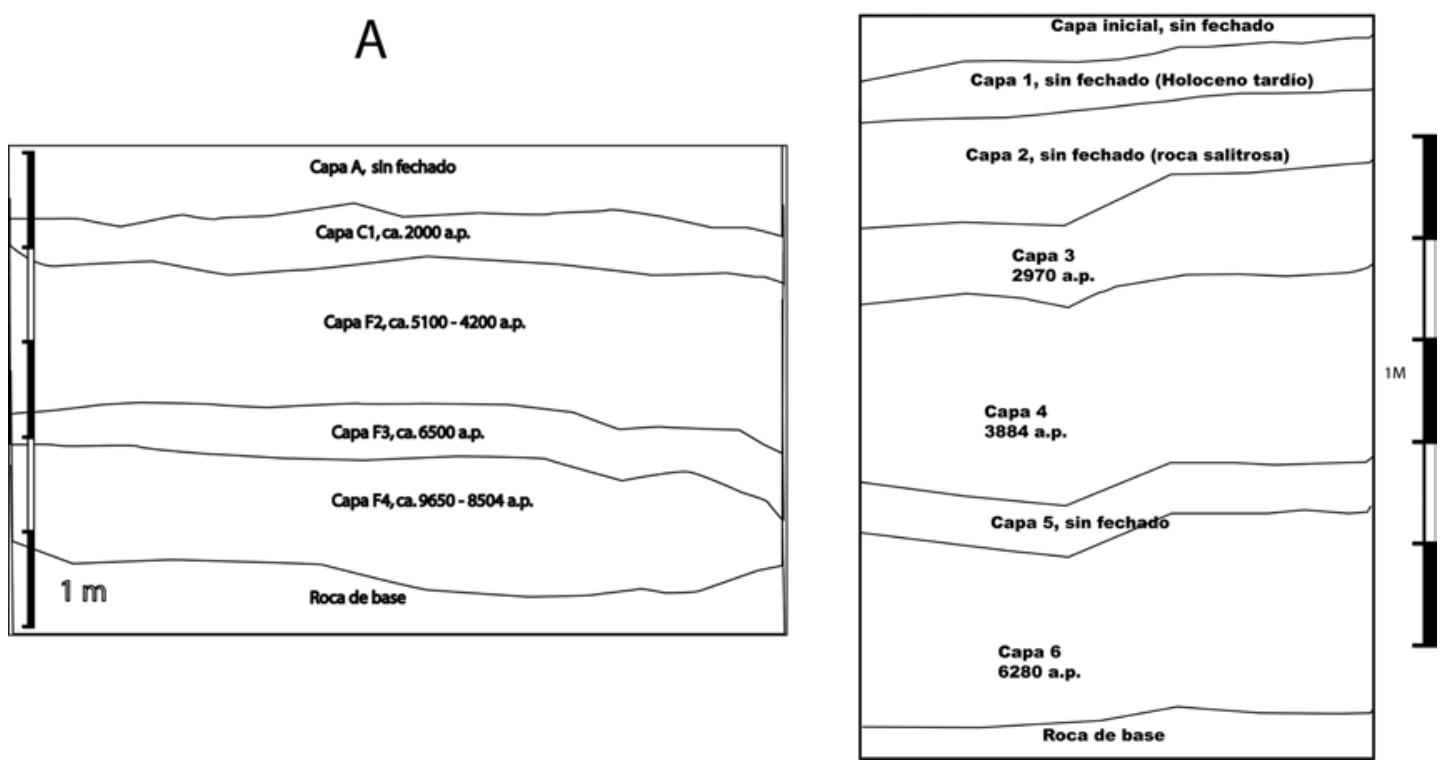

Figura 3. A. Estratigrafía del sitio Alero Cuevas. B. Estratigrafía del sitio Abrigo Pozo Cavado.

A. Stratigraphic cut, Alero Cuevas site. B. Stratigraphic cut, in Abrigo Pozo Cavado site.

la roca de base. En el caso del sitio Alero Cuevas la profundidad vertical promedio es de $1 \mathrm{~m}$, mientras que en Abrigo Pozo Cavado se excavó hasta 1,40 $\mathrm{m}$ de profundidad.

Finalmente, es importante aclarar que el sitio Alero Cuevas presenta un amplio refugio, ya que tiene casi $20 \mathrm{~m}$ de ancho por casi $9 \mathrm{~m}$ de profundidad horizontal a la línea de goteo en algunos sectores. Por su parte, Abrigo Pozo Cavado tiene alrededor de $30 \mathrm{~m}$ de ancho en línea recta por $3 \mathrm{~m}$ a la línea de goteo en la parte más profunda. Sin embargo, la existencia de bloques caídos del techo podría señalar que la superficie de refugio pudo ser mayor en el pasado.

\section{Antecedentes y aspectos teóricos}

Las primeras ocupaciones humanas de la puna argentina comenzaron en el Holoceno Temprano y en general la evidencia parece indicar la presencia 
Tabla 1. Cronología absoluta de los sitios Alero Cuevas y Abrigo Pozo Cavado.

Radiocarbon dates from Alero Cuevas and Abrigo Pozo Cavado.

\begin{tabular}{|c|c|c|c|}
\hline Sitio & Laboratorio & $\begin{array}{c}\text { Fechado } \\
\text { a.p. }\end{array}$ & Muestra \\
\hline Alero Cuevas AC/C2/X & AA 66544 & $643 \pm 35$ & vegetal \\
\hline Alero Cuevas AC/C1-C1 & LP- 1671 & $2.020 \pm 60$ & vegetal \\
\hline Alero Cuevas AC/ C7- C1 & AA90385 & $2.277 \pm 54$ & óseo \\
\hline Alero Cuevas AC/C2-F2 & LP- 1655 & $4.210 \pm 70$ & óseo \\
\hline Alero Cuevas AC/C7-F2 & AA90383 & $5.106 \pm 68$ & carbón \\
\hline Alero Cuevas AC/C1-F3 & AA 71137 & $6.506 \pm 58$ & óseo \\
\hline Alero Cuevas AC/C2/ F3 & LP- 1759 & $6.510 \pm 80$ & carbón \\
\hline Alero Cuevas AC/ C2-F4 & AA71135 & $8.504 \pm 52$ & carbón \\
\hline Alero Cuevas AC-C2- F4 & AA 71136 & $8.838 \pm 52$ & carbón \\
\hline Alero Cuevas AC- C4- F4 final & LP- 1736 & $9.650 \pm 100$ & carbón \\
\hline Abrigo Pozo Cavado APC/C1 - C6 & LP- 2631 & $6.280 \pm 90$ & óseo \\
\hline Abrigo Pozo Cavado APC/ C1 - C4 & AA90384 & $3.884 \pm 59$ & óseo \\
\hline Abrigo Pozo Cavado APC/C1 - C3 & LP- 2636 & $2.970 \pm 80$ & óseo \\
\hline
\end{tabular}

de grupos pequeños y muy móviles, pero con recurrencia en el uso de determinados lugares, especialmente abrigos rocosos (Yacobaccio y Vilá 2002). La evidencia paleoambiental indica que el Holoceno Temprano fue en términos generales más húmedo y con una distribución menos segmentada de los recursos que en la actualidad. Esta situación habría comenzado a cambiar hacia el Holoceno Medio (ca. 8.000-4.000 a.p.), con un clima más seco en términos generales pero con la persistencia de condiciones húmedas en determinados ambientes locales (Núñez et al. 2005; Olivera et al. 2004: Yacobaccio y Morales 2005).

Hacia finales del Holoceno medio (ca. 5.5003.500 a.p.) esta segmentación ambiental habría propiciado procesos de circunscripción espacial, agregación, reducción de la movilidad residencial y aumento de las presiones dependientes de la densidad poblacional (Aschero 1994; López 2009b; Muscio 2004; Yacobaccio 2001). En este contexto, a partir de modelos de optimización y minimización del riesgo de la ecología evolutiva (Boone 1992; Broughton 1999) se espera un uso más intenso pero diversificado de los distintos espacios, incluyendo aquellos considerados subóptimos.

Por otra parte, se espera el aumento de mecanismos de transmisión cultural sesgada (Boyd y Richerson 1985). Así, en contextos de mayor presión poblacional y demanda energética la transmisión cultural permite minimizar los costos de error en la replicación de determinados comportamientos (e.g. estrategias tecnológicas). De esta manera, determinadas tecnologías pueden aumentar su frecuencia por su valor adaptativo en este contexto y disminuir en otro contexto. Estos procesos dejarían una señal arqueológica en el cambio (aumento y disminución) de determinadas clases artefactuales.

En estas condiciones podrían haberse desencadenado cambios importantes en las adaptaciones humanas, tal como se deriva de modelos de optimización como el de tamaño óptimo de grupos en el marco de la ecología evolutiva (Boone 1992). Entre los cambios mencionados ampliamente en la literatura arqueológica están aquellos vinculados a los procesos de intensificación y domesticación de camélidos (Yacobaccio 2001). Se considera intensificación a la búsqueda del incremento de la productividad en el ingreso energético por unidad de recurso o espacio (Broughton 1999). En este sentido, la intensificación puede llevar a cambios no sólo económicos, sino tecnológicos, ya que la tecnología puede incrementar o disminuir la tasa de retorno dependiendo del contexto ecológico y social.

En el Norte de Chile la evidencia de estos procesos de cambio es fuerte en sitios como Tulán 52 y Puripica 1 (Núñez 1992). A diferencia de la puna argentina, en estos sitios de fines del Holoceno Medio y comienzos del Holoceno Tardío (ca. 5.0004.000 a.p.) es notable la presencia de estructuras arquitectónicas agrupadas, con evidencia de cambios relacionados con procesos de intensificación y domesticación de camélidos (Cartajena et al. 2007).

En la puna argentina la mayor parte de la evidencia de estos procesos proviene de abrigos rocosos. Sitios como Alero Unquillar, Huachichocana III e Inca Cueva 7, en la puna de Jujuy, presentan evidencias osteométrica y alométrica de cambios hacia la domesticación de camélidos (Yacobaccio 
2001). Igualmente, a nivel general, en la puna argentina la evidencia directa de estos cambios es reducida, dadas las escasas muestras disponibles para medición. Por este motivo es importante avanzar también en indicadores de cambios en conjunto para abordar problemáticas tan complejas, considerando distintos tipos de evidencias (e.g. zooarqueológica y tecnológica).

A lo largo del Holoceno Tardío los cambios se profundizan en toda la puna, con la consolidación de un nicho económico basado en la producción de alimentos fundamentalmente pastoril y el desarrollo de nuevas tecnologías como la cerámica (Olivera 2001).

\section{Aspectos metodológicos}

La metodología de análisis en las cuencas de Pastos Grandes y Pocitos implicó una perspectiva distribucional para el registro de material arqueológico en superficie y en capa (López 2012). Esto implicó la realización de transectas y sondeos de $0,5 \times 0,5 \mathrm{~m}$ en distintos sectores. Igualmente, en la actualidad una de las prioridades de investigación es ampliar la superficie excavada en los sitios que son el eje de este trabajo.

La prioridad aquí es analizar el cambio en las ocupaciones humanas de los sitios Alero Cuevas y Abrigo Pozo Cavado, por lo que se considerarán muestras de distintas capas con fechados absolutos. Por el momento se prefirió no discutir la evidencia correspondiente a aquellas capas no fechadas, más allá de la asignación por indicadores cronológicos relativos.

Las capas analizadas en el sitio Alero Cuevas corresponden al Holoceno Temprano, Medio y Tardío. Se trata de las capas F4 (ca. 9.650-8.504 a.p.), F3 (ca. 6.500 a.p.), F2 (ca. 5.100-4.200 a.p.) y C1 (ca. 2.000 a.p.). Por su parte, en el Abrigo Pozo Cavado se consideraron los tres conjuntos recuperados de las capas fechadas, correspondientes al Holoceno Medio y Tardío. Ellas son: la capa 3 (2.970 a.p.), la capa 4 (3.884 a.p.) y la capa 6 (6.280 a.p.).

Las dos clases de evidencia consideradas son los restos arqueofaunísticos y el material lítico. Ambas clases de evidencia se encuentran representadas en alta frecuencia en las distintas capas y son importantes para analizar y discutir cambios económicos y tecnológicos.

A los fines del interés de investigación en este trabajo, los estudios zooarqueológicos se centraron en indicadores probables de intensificación y domesticación de camélidos. En primer lugar se consideró la representación de estos recursos en NISP (Número de Especímenes Identificados por Taxón), expresados porcentualmente (NISP\%). Se analizó su variabilidad a lo largo del Holoceno en Abrigo Pozo Cavado y en Alero Cuevas, incluyendo osteometría dentro de especímenes de camélidos para determinar diversidad interespecífica. La osteometría se realizó siguiendo los criterios de Elkin (1996), y se llevaron a cabo análisis de distancia de logaritmos para evaluar la variabilidad interespecífica entre especímenes actuales y arqueológicos (Meadow 1987). También se determinaron variaciones en el tiempo en la representación de especímenes con marcas antrópicas (incluyendo corte, machacado, percusión, raspado y negativos de impacto -Mengoni Goñalons 1999-), para analizar cambios posibles en la intensidad de procesamiento de camélidos. Por último, se analizó la variación en la representación de especímenes fusionados y no fusionados de camélidos, como una manera de abordar cambios en el perfil etario relacionados con procesos de intensificación y domesticación (Broughton 1999; Wheeler 1998). En este último análisis es importante señalar la escasez de otros indicadores etarios, debido a la fragmentación de los conjuntos (e.g. dentición). Los aspectos tafonómicos de los conjuntos fueron exhaustivamente desarrollados en trabajos previos (ver López 2009b, 2012).

En relación con el material lítico, se analizaron indicadores de cambio morfológico y tecnológico. En primer lugar se analizó la diversidad morfológica de puntas de proyectil y otros instrumentos que pueden considerarse indicadores cronológicos relativos (Jones y Beck 1992). Su comparación con material lítico proveniente de contextos de superficie y más generalmente en una perspectiva regional se convierte en un indicador del aumento y la disminución de ciertas clases de artefactos en relación con mecanismos de transmisión cultural. Para analizar cambios tecnológicos se estudió la forma base de los instrumentos (Aschero 1983), y también la variación en el uso de materias primas. A los fines de análisis en los casos de estudio, se denominan locales aquellas materias primas procedentes de la misma cuenca en la que se encuentran los sitios arqueológicos investigados, en una extensión lineal no mayor a 20 o $25 \mathrm{~km}$. Por su parte, las no locales son aquellas que se encuentran afuera de este rango.

Tanto la forma base de los instrumentos como la variación en el uso de materias primas resultan 


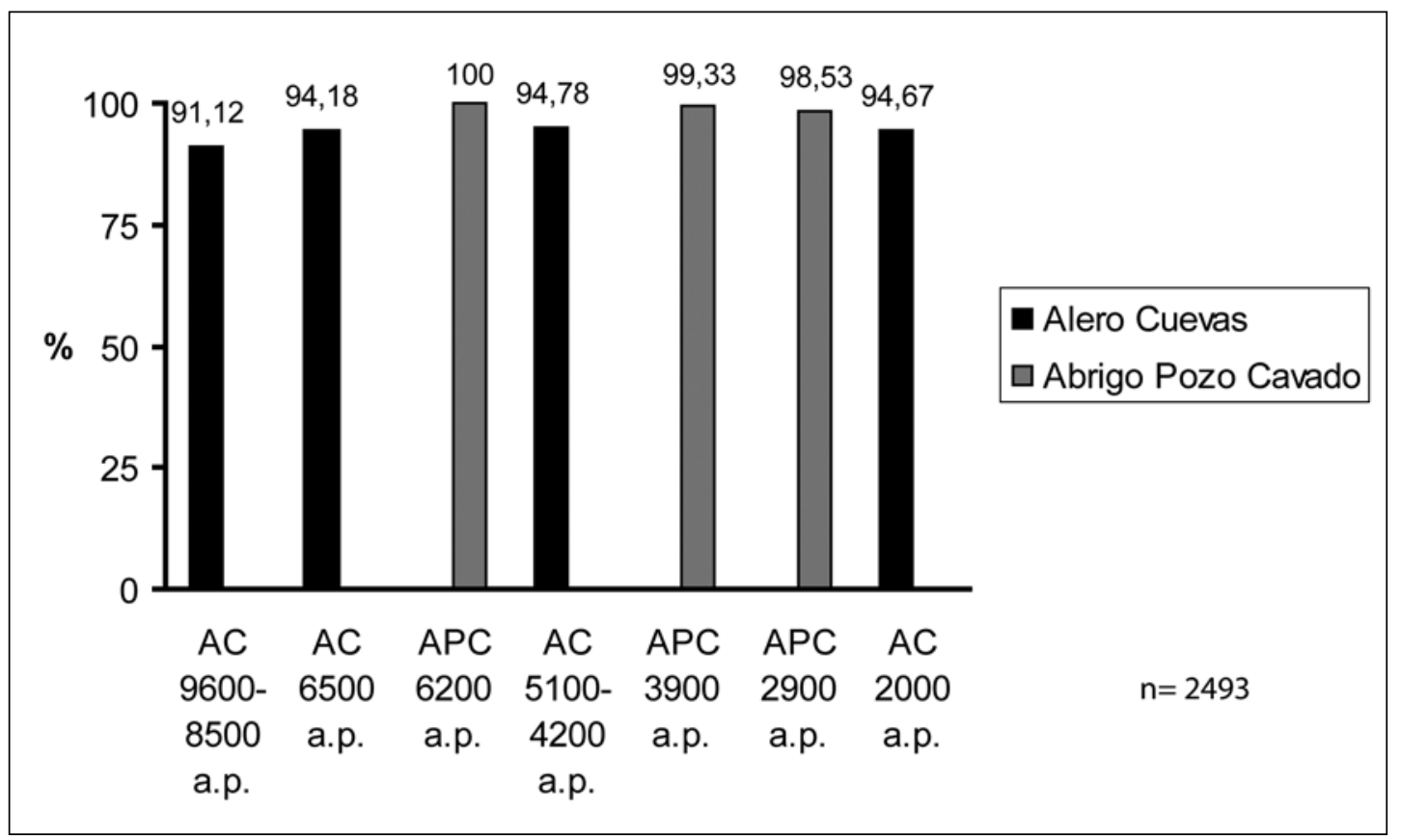

Figura 4. NISP \% de camélidos en Alero Cuevas y Abrigo Pozo Cavado.

NISP \% of camelids, Alero Cuevas and Abrigo Pozo Cavado.

aspectos importantes para analizar cambios en las estrategias tecnológicas (Bousman 1993; Nelson 1991), que serán discutidos en relación con procesos de intensificación y domesticación de camélidos.

\section{Resultados}

\section{Zooarqueología}

La diversidad taxonómica en los sitios Alero Cuevas y Abrigo Pozo Cavado es muy baja. Este mismo patrón se repite a lo largo de los Andes centro sur (Yacobaccio 2001). En los dos sitios los camélidos dominan todos los conjuntos al nivel de familia en NISP \% (Figura 4). Para controlar la variación interespecífica dentro de los camélidos se realizaron mediciones osteométricas, que actualmente se encuentran en proceso de análisis ante la necesidad de aumentar la muestra arqueológica y actual usada como estándar. Por el momento se registró una variación métrica entre especímenes, especialmente en las falanges primeras $(\mathrm{N}=42)$, las cuales son usadas recurrentemente a lo largo de los Andes centro sur para la discriminación de camélidos y por este motivo presentan valor comparativo (Mengoni Goñalons y Yacobaccio 2006). Durante el Holoceno Temprano las mediciones corresponderían a vicuñas (Vicugna vicugna) y guanacos (Lama guanicoe), estos últimos de tamaños más grandes que en la actualidad. Esto se debería a un tamaño mayor de los guanacos hacia el Holoceno Temprano y menor a partir del Holoceno Medio, lo que fue señalado regionalmente por Mengoni Goñalons y Yacobaccio (2006). A partir de finales del Holoceno Medio se evidencian cambios osteométricos en la capa F2 del sitio Alero Cuevas y en la capa 4 de Abrigo Pozo Cavado. En particular se destacan mediciones correspondientes a tamaños de vicuña, otras similares al estándar de guanaco actual y algunas más grandes, comparables a valores de llamas actuales (ver López y Restifo 2012). Este contexto es interesante, porque la evidencia regional de la puna argentina y el Norte de Chile indica cambios hacia la domesticación de camélidos (Cartajena et al. 2007; Mengoni Goñalons y Yacobaccio 2006). En relación con las capas fechadas en el Holoceno Tardío en ambos sitios, se evidencian valores osteométricos posiblemente correspondientes a llamas, en un contexto regional en el que se consolidaron nichos económicos con estrategias pastoriles. En este contexto se han registrado evidencias de estructuras asignables a corrales en sitios cercanos al Alero Cuevas y con fechas correspondientes al Holoceno Tardío. De 


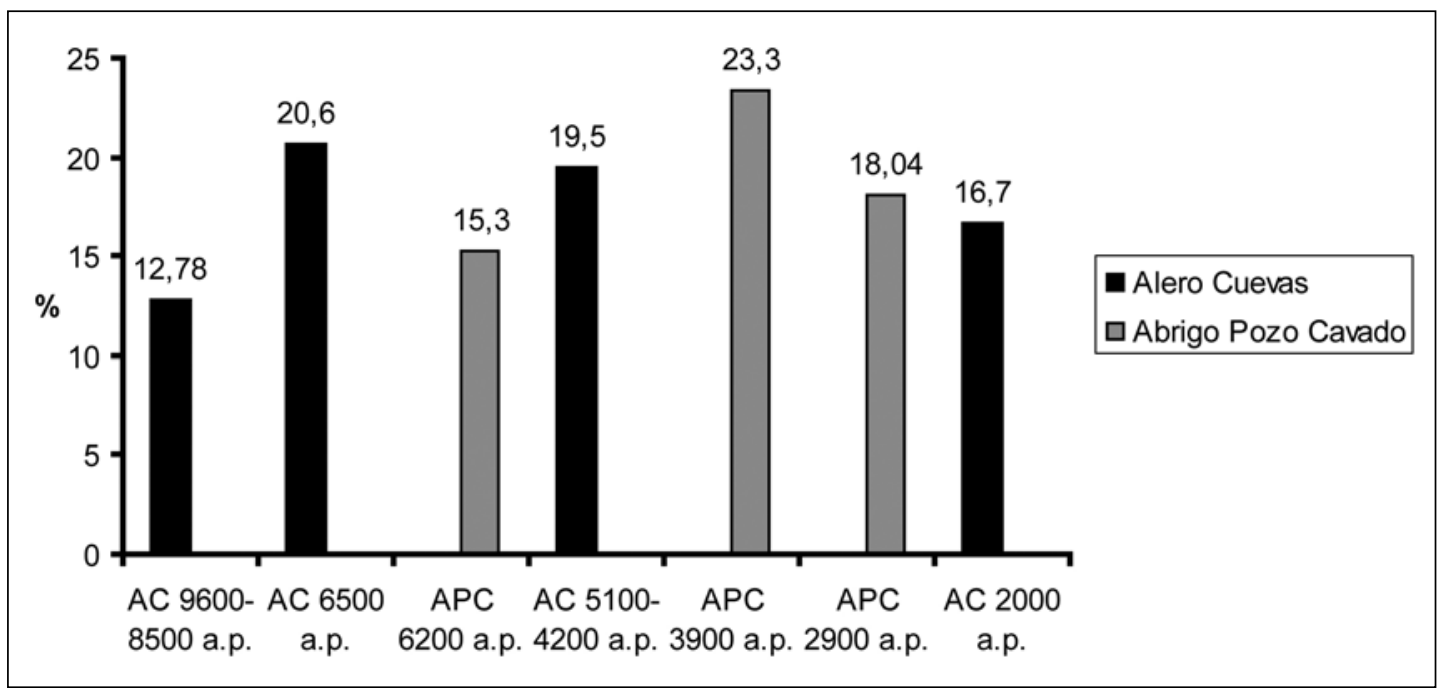

Figura 5. Porcentaje de especímenes de camélidos con marcas antrópicas en Alero Cuevas y Abrigo Pozo Cavado sobre el NISP total $(\mathrm{n}=2493)$.

Percentage of specimens of camelids with anthropic marks in Alero Cuevas and Abrigo Pozo Cavado from a total NISP ( $n=2493)$.

todas formas, debido a la presencia de especímenes asignables a vicuñas y diversas puntas de proyectil, se postula que el componente cazador en el nicho económico habría sido alto. La caza de camélidos silvestres está registrada a lo largo de todas las tierras altas del Noroeste argentino y el Norte de Chile, aun en contextos donde el pastoreo es la estrategia económica predominante (Yacobaccio et al. 1994).

En general, todos los conjuntos presentan una alta integridad, dado que el agente humano fue el principal responsable en la formación de los mismos (para un análisis tafonómico exhaustivo ver López 2009a, 2012). La presencia de marcas antrópicas muestra variabilidad entre los conjuntos (Figura 5). El cambio más notable está representado en la capa 4 del sitio Abrigo Pozo Cavado, fechada hacia fines del Holoceno Medio y comienzos del Holoceno Tardío. Allí se detecta un aumento de los especímenes con marcas antrópicas. En el caso del sitio Alero Cuevas, la frecuencia de marcas antrópicas aumenta a partir del Holoceno Medio.

En relación con el estado de fusión, se detectan cambios notables hacia fines del Holoceno Medio en los dos sitios analizados (Figura 6 A, B). El aumento notable de especímenes no fusionados de camélidos en la capa 4 del sitio Abrigo Pozo Cavado y en la capa F2 del sitio Alero Cuevas indica un incremento importante en el consumo de subadultos, incluyendo neonatos (28\% de neonatos en Abrigo
Pozo Cavado y $32,1 \%$ de neonatos en el sitio Alero Cuevas). En este sentido, en el sitio Abrigo Pozo Cavado hay evidencia de marcas antrópicas sobre especímenes de neonatos. Asimismo, su presencia indica al menos la ocupación durante el verano, momento de parición de los camélidos.

\section{Material lítico}

A lo largo de las capas analizadas se destaca la variación en determinadas clases artefactuales sensitivas del tiempo o cronológicamente diagnósticas (Jones y Beck 1992). Así, algunas clases de artefactos pueden dar cronología relativa a contextos que no pueden ser fechados de forma absoluta (e.g. contextos de superficie).

En este sentido, en la capa del Holoceno Temprano del sitio Alero Cuevas se evidencia la recurrencia de puntas de proyectil triangulares apedunculadas (Figura 7A). Esta clase de puntas se presenta en distintos contextos fechados en el Holoceno Temprano de la puna argentina y el norte de Chile (Aschero y Martínez 2001; Núñez et al. 2005).

A lo largo del Holoceno Medio, en Pocitos se evidencia tanto en superficie como en capa una alta diversidad de puntas de proyectil diagnósticas de esta cronología (López et al. 2012). Por el contrario, la diversidad de clases artefactuales cronológicamente diagnósticas del Holoceno Medio es menor 

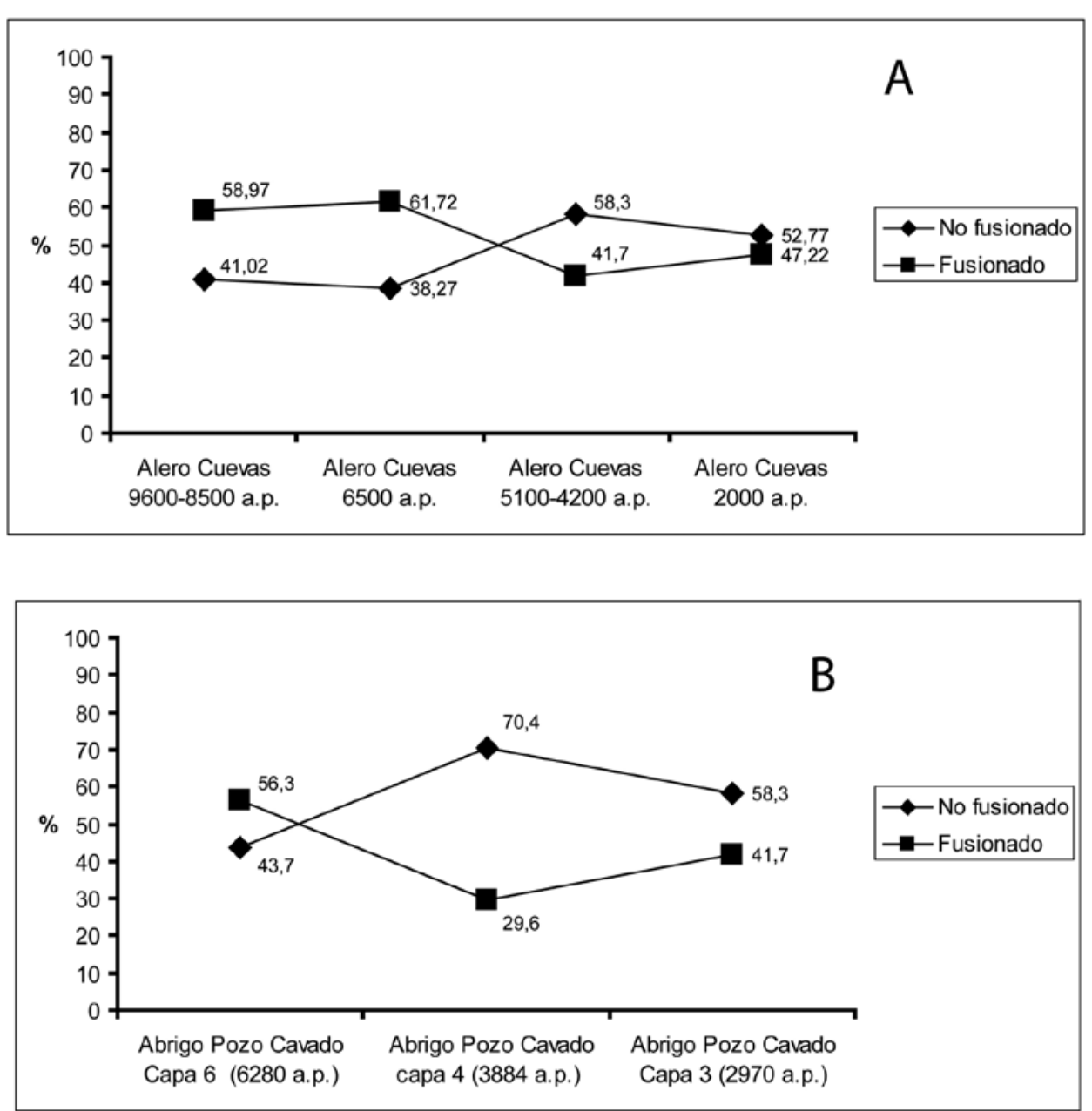

Figura 6. Porcentaje de especímenes de camélidos fusionados y no fusionados sobre la muestra en la que se pudo determinar el estado de fusión (n=673). A. Alero Cuevas. B. Abrigo Pozo Cavado.

Percentage of fused and unfused specimens of camelids of sample on which state of fusion was evident (n=673). A. Alero Cuevas. B. Abrigo Pozo Cavado.

en Pastos Grandes. En esta área, la clase artefactual más recurrente corresponde a artefactos lanceolados unifaciales confeccionados sobre tecnología de hojas o extracciones laminares. Con esta tecnología se obtienen formas alargadas de bordes laterales paralelos o subparalelos con una relación entre el largo y el ancho del doble o más, a partir de núcleos preparados con este objetivo.

Entre las clases artefactuales tiempo-sensitivas del Holoceno Medio se registró en contextos de superficie de Pocitos una clase de punta de proyectil de base escotada y bordes paralelos rectilíneos (Figura 7B), fragmentada, y ausente en Pastos
Grandes, similar al "tipo" Quebrada Seca C, en la puna de Catamarca (Aschero y Martínez 2001); también se registró una clase de punta de proyectil lanceolada de bordes paralelos o subparalelos, con tamaños variables, algunas de tamaño promedio de alrededor de $6 \mathrm{~cm}$ de largo recuperadas en la capa de ca. 6.280 a.p. del Abrigo Pozo Cavado y en la capa de ca. 6.500 a.p. de Alero Cuevas, y otras de bordes rectos o rectilíneos paralelos recuperadas en contextos de superficie de Pocitos (Figura 7C), similares a las definidas como Peñas de la Cruz A en la puna de Catamarca (Aschero y Martínez 2001); otra clase es una punta triangular alargada, presente en la 


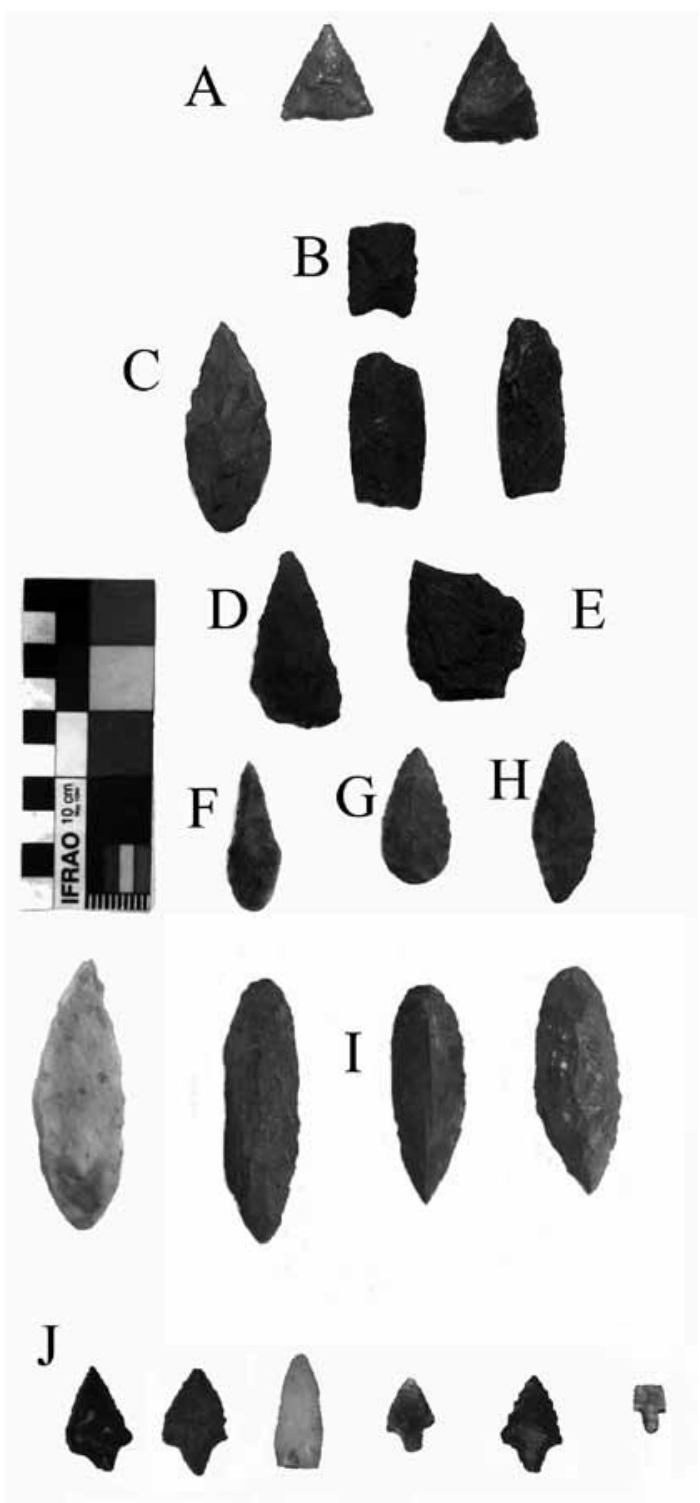

Figura 7. A-J. Artefactos tiempo-sensitivos del Holoceno Temprano, Medio y Tardío en Pastos Grandes y Pocitos (ver descripción en el texto).

Time-sensitive artefacts of the early, middle, and late Holocene in Pastos Grandes and Pocitos (see description in the text).

capa de ca. 6.280 a.p. del sitio Abrigo Pozo Cavado (Figura 7D); también se registró en superficie en Pocitos una clase de punta con pedúnculo destacado y aletas (Figura 7E), ausente en Pastos Grandes y comparable al "tipo" Quebrada Seca B del Holoceno Medio en la puna de Catamarca (Hocsman 2006); otra clase registrada es una punta con pedúnculo esbozado, base convexa y reactivación en el limbo (Figura 7F) recuperada en la capa 4 del sitio Abrigo
Pozo Cavado con una fecha de 3.884 a.p., ausente en Pastos Grandes y comparable a algunas en Quebrada Seca 3 o Chaschuil en Catamarca (Ratto 2003); otras clases de puntas con frecuencias altas hacia fines del Holoceno medio en distintos contextos de la Puna son las lanceoladas chicas de base convexa, halladas en capa en Abrigo Pozo Cavado y en la capa de ca. 5.100-4.200 a.p. del sitio Alero Cuevas (Figura 7G), y las denominadas bipuntas, halladas en la capa 4 de ca. 3.884 a.p. del sitio Abrigo Pozo Cavado, similares a las lanceoladas chicas, pero en vez de tener una base convexa u ovalada, tienen un doble ápice (Figura 7H).

Otra clase de artefactos diagnósticos de cronología son los lanceolados unifaciales confeccionados sobre tecnología de hojas, que presentan bordes paralelos o subparalelos, con filos largos laterales y unifaciales (Figura 7I). En general tienen un retoque pequeño sobre el bulbo, posiblemente para reducir la pieza para el enmangue. Su cronología corresponde a finales del Holoceno Medio, con fechados en capa en el sitio Alero Cuevas entre ca. 5.100 y 4.200 a.p. en asociación con un núcleo de hojas. La distribución y frecuencia de estos instrumentos en capa y en superficie es muy alta en Pastos Grandes (>100), en general asociados con núcleos de hojas, mientras que por el momento su presencia en Pocitos es escasa (sólo dos especímenes registrados en superficie). En el sitio Ramadas, en San Antonio de los Cobres, puna de Salta, a una distancia de $60 \mathrm{~km}$ de Pastos Grandes, estos artefactos se encuentran fechados en capa en ca. 5.200 a.p. (Muscio 2004). Esta clase de artefactos también se encuentra en la puna de Jujuy, en el área de Salinas Grandes (Fernández Distel 1978), y fueron adscritos a la "industria saladillense" con un fechado de ca 5.500 a.p. en el sitio Río Grande (Fernández 1983). Si bien Fernández (1983) habla de puntas Saladillo para señalar muchos de estos artefactos sobre tecnología de hojas en la puna de Jujuy, en el caso de los artefactos lanceolados unifaciales en la puna de Salta se plantea que los filos largos serían fundamentalmente aptos para el procesamiento de recursos, en especial los camélidos (López 2009b).

La emergencia y proliferación de tecnología de hojas en Pastos Grandes y claramente circunscrita a la capa de ca. 5.100-4.200 a.p. del sitio Alero Cuevas, representa el cambio tecnológico más importante en el material lítico. Esta tecnología está presente en este contexto cronológico asociada a los artefactos 


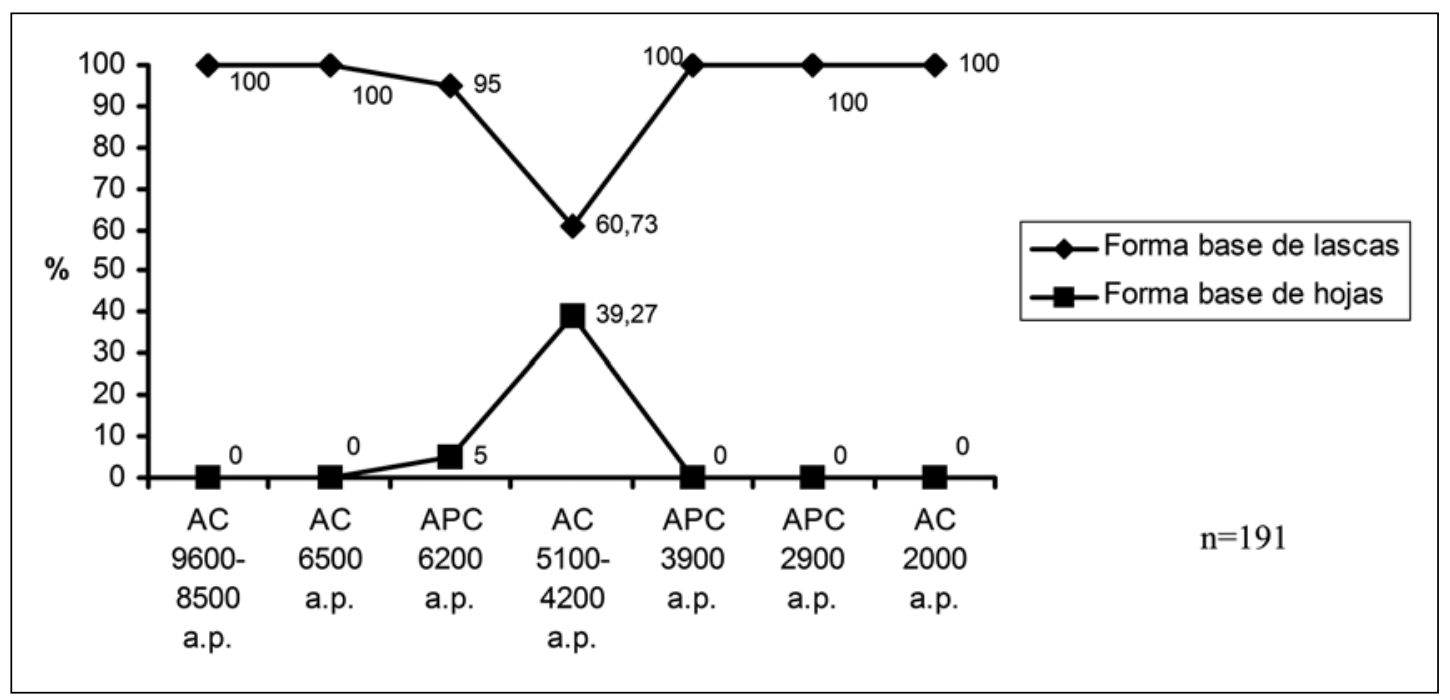

Figura 8. Lascas y hojas como formas base de instrumentos en Alero Cuevas y Abrigo Pozo Cavado.

Flake and blade technology as tool blanks in Alero Cuevas and Abrigo Pozo Cavado.

lanceolados unifaciales y está ausente tanto en el Holoceno Temprano como en el Holoceno Tardío (Figura 8).

La declinación de la tecnología de hojas hacia el Holoceno Tardío es evidente en la capa de ca. 2.000 a.p. del sitio Alero Cuevas. En el caso de Pocitos las hojas como forma base aparecen en muy baja frecuencia en la capa de 6.200 a.p. (Figura 8). Sin embargo, en Pocitos por el momento no se recuperaron núcleos de hojas en capa ni su asociación con los artefactos lanceolados unifaciales. En consecuencia, es importante la variabilidad regional evidenciada cuando se comparan ambas áreas, fundamentalmente a lo largo del Holoceno Medio y comienzos del Holoceno Tardío.

Durante el Holoceno Tardío, en las capas analizadas de ambos sitios, la tecnología de lascas es la forma base de todos los instrumentos. Entre las puntas de proyectil se destaca la representación de triangulares chicas con pedúnculo y lanceoladas chicas (Figura 7J).

En relación con el uso de materias primas, es notable el cambio que se evidencia en la capa de ca. 5.100-4.200 a.p. del sitio Alero Cuevas (Figura 9A). En este contexto aumentan notablemente las materias primas locales (particularmente andesitas) y disminuyen las no locales (las obsidianas). Las materias primas locales, en conjunto, superan el $50 \%$ en esta capa, sumando andesitas y otras locales, mientras que las obsidianas no locales decrecen de valores mayores a 70\% a menos del 50\% (Figura 9A). Sin embargo, en la capa 4 del sitio Abrigo Pozo Cavado, ubicado hacia fines del Holoceno Medio y comienzos del Holoceno Tardío, la representación de obsidianas sigue siendo predominante aunque con un aumento de la obsidiana local (Figura 9B). Específicamente, la obsidiana local en Pocitos es la que proviene de Quirón, un sector dentro de esta cuenca (Figura 10), la cual es no local en relación con Pastos Grandes. Esta materia prima se encuentra bien representada tanto en el Abrigo Pozo Cavado como en Alero Cuevas. Respecto de las andesitas de Pocitos aún no se pudo determinar su fuente, pero no se descarta que provengan de la fuente denominada Picadero, en Pastos Grandes. En este caso la capa de 3.884 a.p. del Abrigo Pozo Cavado mostraría una disminución de materias primas no locales procedentes de Pastos Grandes (andesita).

También es importante la presencia de otras obsidianas procedentes de distintas fuentes como Zapaleri, en el límite entre Bolivia, Chile y Jujuy, a más de $150 \mathrm{~km}$ de distancia de ambos sitios; Archibarca y Ona en Catamarca a más de 100 km; Tocomar a más de $40 \mathrm{~km}$ de Alero Cuevas y casi 100 de Abrigo Pozo Cavado; y una obsidiana de color gris, que es similar en su forma química a algunas recuperadas en la Quebrada de Tulán (Mercuri y Glascock 2011). La frecuencia de esta última obsidiana es alta en la capa de fines del Holoceno 


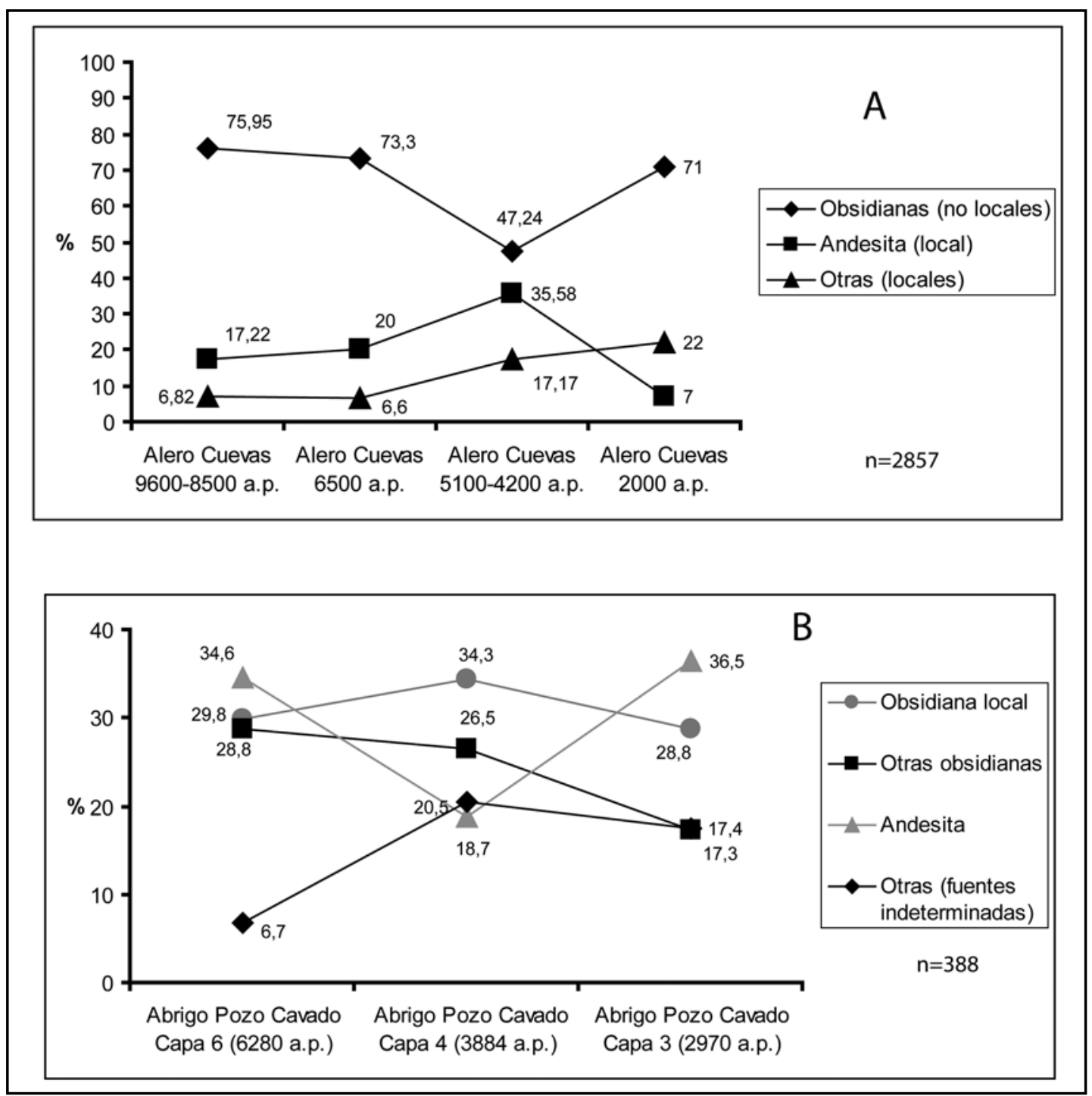

Figura 9. Representación de materias primas en conjuntos líticos (instrumentos y desechos de talla). A. Alero Cuevas. B. Abrigo Pozo Cavado.

Representation of raw material in lithic assemblages (debitage and tools). A. Alero Cuevas. B. Abrigo Pozo Cavado.

Medio de Abrigo Pozo Cavado y escasa en este contexto cronológico del sitio Alero Cuevas. En la Figura 10 se observan las distintas fuentes de las obsidianas que fueron utilizadas en la confección de instrumentos en los sitios Alero Cuevas y Abrigo Pozo Cavado.

\section{Discusión y Conclusiones}

La información arqueológica de los sitios Abrigo Pozo Cavado y Alero Cuevas aporta nuevos datos para ser analizados en perspectiva regional no sólo en la mesoescala de las cuencas de Pastos Grandes y Pocitos sino también en la macroescala de los Andes centro sur. Los análisis presentados hasta el momento no deben ser vistos como concluyentes, ya que ambos sitios se encuentran en proceso de excavación y obtención de nuevos fechados. En este sentido, como punto de discusión general se puede señalar que la información arqueológica de ambos sitios indica similitudes y diferencias en los procesos de cambio regional. Más específicamente, se evidencian indicadores compartidos tanto en el uso de fauna como en la tecnología lítica. A su vez, 


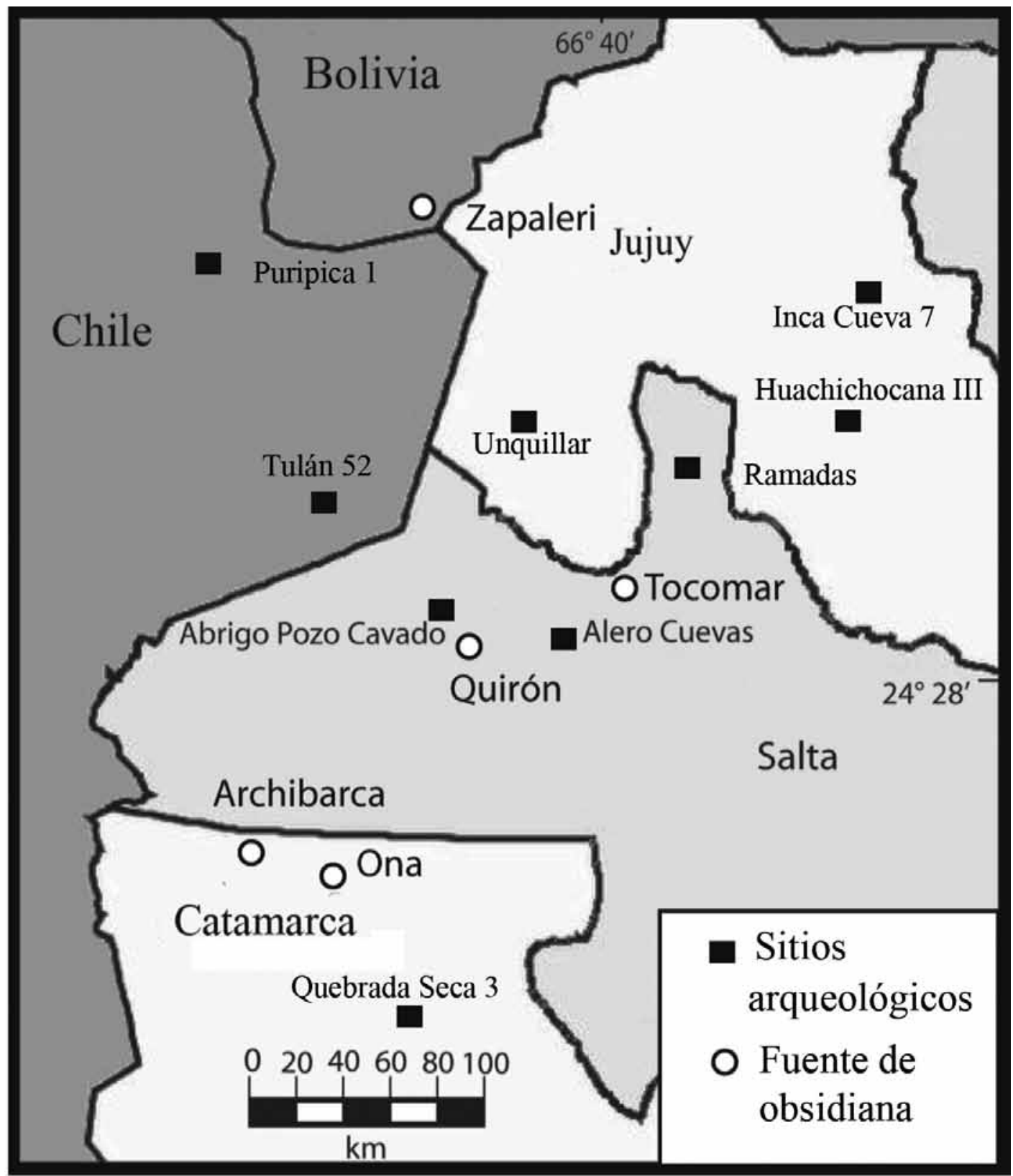

Figura 10. Fuentes de obsidiana utilizadas para la confección de instrumentos en Alero Cuevas y Abrigo Pozo Cavado y ubicación de sitios arqueológicos mencionados en el texto.

Sources of obsidian utilized to make the instruments found at Alero Cuevas and Abrigo Pozo Cavado, and location of archaeological sites cited in the text.

las diferencias son más notables en el análisis del material lítico.

En relación con el uso de fauna en ambos sitios, el registro arqueofaunístico indica que los camélidos fueron los recursos absolutamente predominantes para el consumo humano. La evidencia osteométrica reunida hasta el momento si bien no es concluyente, tal como ocurre en otros sitios de la puna, permite señalar la presencia de especímenes posiblemente correspondientes a vicuñas y guanacos (camélidos silvestres) y llamas (camélidos domesticados). Los cambios en el tamaño de especímenes hacia estándares de llamas actuales y superiores al guanaco andino comienzan en las capas de fines del 
Holoceno Medio y comienzos del Holoceno Tardío en ambos sitios.

A nivel regional para este contexto cronológico se evidencian cambios osteométricos en sitios como Alero Unquillar, Huachichocana III e Inca Cueva 7, en la puna de Jujuy (Yacobaccio 2001), pero si bien la evidencia de estos sitios es sólida, todavía es pequeña, tal como ocurre en Alero Cuevas y Abrigo Pozo Cavado. De todas formas, hay una coincidencia general en que los sitios de la puna argentina reflejan una tendencia probablemente relacionada con la intensificación y domesticación de camélidos, fundamentalmente a fines del Holoceno Medio (Yacobaccio 2001). También en el Norte de Chile, en sitios como Tulán 52 y Puripica 1, la evidencia arqueológica se relacionaría con estos procesos (Cartajena et al. 2007).

Asimismo, los conjuntos arqueofaunísticos de los sitios Alero Cuevas y Abrigo Pozo Cavado permiten señalar cambios importantes en el perfil etario hacia fines del Holoceno Medio. El cambio hacia la representación mayoritaria de especímenes no fusionados en este contexto cronológico puede interpretarse a partir de dos hipótesis no contradictorias. La primera es que este cambio representa una demanda energética mayor producto de presiones dependientes de la densidad poblacional, en un contexto donde se espera circunscripción espacial y agregación humana, en un ambiente altamente segmentado. En distintas áreas, el aumento de subadultos en el registro arqueológico (incluyendo altas proporciones de neonatos) ha sido relacionada desde una perspectiva ecológica evolutiva con presiones poblacionales sobre los recursos (ver Broughton 1999).

La hipótesis alternativa es que este patrón se relacione con los inicios de la domesticación de camélidos, tal como se propuso para sitios de los Andes centrales, en relación con el fuerte consumo de machos subadultos para la propagación del rebaño (dejando sobrevivir a las hembras y unos pocos machos) o infecciones producto del encierro (Moore 1989; Wheeler 1998). Sin embargo, las hipótesis no son opuestas porque a nivel teórico es posible que la presión sobre los recursos de caza haya llevado a la domesticación de camélidos. Por lo tanto, desde los modelos de la ecología evolutiva la domesticación podría ser interpretada como una respuesta adaptativa a mayores presiones sociales y ecológicas hacia fines del Holoceno Medio.
La representación de marcas antrópicas podría ser vista como un indicador de la intensificación en el uso de los camélidos, pero los resultados presentados no son concluyentes. De todas formas se evidencia un aumento de las marcas antrópicas durante el Holoceno Medio en ambos sitios. Inclusive el cambio más importante se observa en la capa de fines del Holoceno Medio y comienzos del Holoceno Tardío del sitio Abrigo Pozo Cavado, lo que podría relacionarse con una intensificación en el procesamiento de recursos. Incluso se detectaron marcas antrópicas sobre especímenes de neonatos. Sin embargo, no hay consenso en que el aumento de marcas antrópicas refleje intensidad de procesamiento, tal como se observó a partir de análisis experimentales (Egeland 2003). Por lo tanto se debe avanzar en la búsqueda de otros indicadores y especialmente en la integración entre distintas líneas de evidencia para dar cuenta de hipótesis de intensificación y domesticación. En este sentido, los análisis del material lítico aportan evidencia que integrada con la zooarqueología pueden permitir el avance en el estudio de los procesos de cambio a nivel regional.

El material lítico es el que mayores diferencias presenta entre Pastos Grandes y Pocitos. Particularmente interesante es la evidencia arqueológica del Holoceno Medio y comienzos del Holoceno Tardío. Tanto en contextos de superficie de Pocitos como en capa en el sitio Abrigo Pozo Cavado resalta la variabilidad de artefactos cronológicamente diagnósticos del Holoceno Medio, fundamentalmente puntas de proyectil. Al contrario, en Pastos Grandes en general y en el sitio Alero Cuevas en particular, las clases artefactuales tiemposensitivas (Jones y Beck 1992) presentan una baja diversidad. Especialmente notable es el caso de los artefactos lanceolados unifaciales sobre forma base de hojas, que se encuentran claramente circunscriptos a la capa de ca. 5.100-4.200 a.p. en el sitio Alero Cuevas. Sin embargo es más importante aún el cambio tecnológico que representa la proliferación de hojas como forma base de estos instrumentos en el contexto arqueológico de fines del Holoceno Medio. Por el momento, en Abrigo Pozo Cavado no se pudo registrar en capa la asociación entre núcleos de hojas y artefactos lanceolados unifaciales, tal como se detectó en el sitio Alero Cuevas. En Pocitos sólo en superficie se registraron dos especímenes de esta clase y una muy baja frecuencia de hojas en la capa de 6.280 a.p. de Abrigo Pozo Cavado. 
En el sitio Alero Cuevas, el cambio tecnológico se asocia también con el cambio en el uso de materias primas. En la capa de fines del Holoceno Medio aumenta notablemente el uso de materias primas locales como la andesita y decrecen las obsidianas no locales. Por el contrario, en Abrigo Pozo Cavado las obsidianas se mantienen constantes.

En Pastos Grandes, la asociación entre materias primas locales como la andesita y la tecnología de hojas es recurrente. Tanto en los núcleos de hoja como en los artefactos lanceolados unifaciales la materia prima predominante es la andesita. Si bien posiblemente haya requerimientos tecnológicos para el uso de esta materia prima en la confección de hojas, se propone hipotéticamente que la asociación de cambios tecnológicos y arqueofaunísticos en Pastos Grandes se relaciona con un contexto más general de cambio. En este sentido, se hace referencia a procesos de agregación humana, mayores presiones dependientes de la densidad poblacional y reducción de la movilidad residencial, lo que aumentaría la presión sobre los camélidos silvestres y desembocaría en cambios relacionados a la domesticación de camélidos e innovaciones tecnológicas.

Se propone que la tecnología de hojas y los artefactos lanceolados unifaciales habrían proliferado en el marco de un cambio en la estrategia tecnológica (Nelson 1991). Este cambio se relacionaría con una estrategia de maximización del rendimiento de los recursos tendiente a la eficiencia (Bousman 1993). La tecnología de hojas permite la estandarización de formas, dando lugar a filos largos con alto rendimiento de uso y fácilmente reemplazables. En este sentido, se plantea como hipótesis su uso para maximizar el rendimiento en el procesamiento de camélidos en contextos en los cuales se intensificó su consumo por una mayor demanda energética. Sin embargo, no se descartan otras funciones potenciales. Los estudios funcionales a futuro permitirán avanzar en esta hipótesis.

Asimismo, se propone una relación estrecha entre la proliferación de tecnología de hojas y mecanismos de transmisión cultural sesgada, en relación con presiones dependientes de la densidad poblacional. Teóricamente se espera que el aprendizaje social aumente en contextos de mayor densidad poblacional y tecnologías más complejas (Boyd y Richerson 1985). Este patrón tecnológico se encuentra no sólo en Pastos Grandes, sino en otras áreas cercanas como San Antonio de los Cobres en la puna de Salta y Salinas Grandes en la puna de
Jujuy. También se evidencia un aumento de la frecuencia de hojas en las quebradas de Tulán y Puripica hacia finales del Holoceno Medio (ca. 5.000-4.000 a.p.), en el Norte de Chile (Núñez 1992). Para esta cronología, en contextos de domesticación inicial de camélidos, sitios como Tulán 52 y Puripica 1 reflejan un patrón de agregación y nucleamiento en sectores específicos del espacio, con alta inversión en estructuras arquitectónicas (Núñez 1992). Sectores de alto descarte de material arqueológico en lugares específicos del espacio durante fines del Holoceno Medio también se evidencian en la puna de Salta -e.g. sitios La Hoyada y Ramadas- (López 2009b; Muscio 2004).

Por otra parte, la ausencia de tecnología de hojas y artefactos lanceolados unifaciales en otras regiones de la puna como Antofagasta de la Sierra en Catamarca, permite considerar la posibilidad de un uso de espacios diferenciados a finales del Holoceno Medio. Esto es concordante con el uso recurrente de materias primas locales propias de las distintas cuencas. De esta manera, el aumento en el uso de materias primas locales en el sitio Alero Cuevas hacia 5.000 a.p., puede ser considerado un indicador de reducción de la movilidad residencial (Kelly 1992). Tampoco se descarta que estos cambios en el material lítico estén representando marcadores de diferencias o control territorial, como propuso Aschero (2011) para otros contextos de la puna.

En Pocitos, a diferencia de Pastos Grandes, durante el Holoceno Medio hay una alta diversidad de clases de puntas de proyectil. Las puntas de proyectil comparten patrones con distintas áreas de la puna seca y salada, incluyendo Antofagasta de la Sierra. Esta diversidad no se repite en Pastos Grandes. A esto se debe sumar la presencia en Pocitos de obsidiana gris, también evidenciada en el Norte de Chile. Por lo tanto, durante el Holoceno Medio y comienzos del Holoceno Tardío Pocitos y Pastos Grandes muestran diferencias que podrían relacionarse al contexto ecológico y social.

En Pastos Grandes la presencia de amplios sectores con agua permanente facilitaría la instalación residencial humana. Por el contrario, las condiciones de ambiente más árido de Pocitos (subóptimo en términos ecológico-evolutivos en relación con Pastos Grandes), darían lugar a un área abierta a la circulación de personas, recursos e información cultural. Así, se plantea que a partir del Holoceno Medio la extrema segmentación del ambiente generó condiciones aptas para la circunscripción espacial, 
la competencia y la agregación humana, lo que propiciaría a su vez un aumento del tamaño de los grupos (Aschero 1994; López 2009a). A medida que disminuyen los espacios de alto ranking se espera que los grupos humanos también ocupen los espacios de menor ranking o incluso subóptimos, pero aún disponibles para la ocupación (Boone 1992). Esto podría explicar las intensas ocupaciones humanas que existen en Pocitos durante el Holoceno Medio y comienzos del Holoceno Tardío en el borde del salar. A su vez, durante el Holoceno Medio esta menor calidad del ambiente daría lugar a un contexto de menor competencia por este espacio y movimientos e interacción más alta con distintas áreas de la puna, al contrario de Pastos Grandes. Los estudios paleoambientales a nivel local a futuro permitirán profundizar estas hipótesis. En este sentido, los análisis llevados a cabo en otras áreas de la puna argentina, tanto seca (Yacobaccio y Morales 2005) como salada (Olivera et al. 2004), dan cuenta de esta variabilidad ambiental a partir del Holoceno Medio.

Finalmente, desde el Holoceno Tardío se habría establecido a lo largo de la puna de Salta un nicho económico basado en el pastoreo y la caza de camélidos. Esta diversificación de las estrategias económicas habría permitido minimizar el riesgo (Escola 2002) y reorganizar los grupos en unidades domésticas más pequeñas, tal como se observa en los pastores actuales de la puna (Göbel 2001). Esto no implica decrecimiento poblacional, sino reorganización al nivel de los grupos. De esta forma, ante una estrategia pastoril consolidada, las presiones sobre los recursos de caza habrían disminuido como consecuencia de una menor demanda energética sobre los mismos. Así, tecnologías complejas como las hojas serían menos eficientes en este nuevo contexto. Esto explicaría su declinación en el registro arqueológico de Pastos Grandes. Por el contrario, en contextos de intensificación y domesticación inicial de camélidos la tecnología de hojas habría formado parte de una estrategia adaptativa tendiente a maximizar el rendimiento de los recursos, fundamentalmente en el procesamiento de camélidos. También es importante destacar el aumento de obsidianas no locales a partir del 2.000 a.p., lo que podría ser interpretado en relación con interacciones sociales para minimizar el riesgo (Yacobaccio et al. 2004).

En conclusión, la integración de la información arqueológica de ambos sitios y su comparación regional indica procesos distintivos, pero también compartidos. La profundización de la investigación permitirá avanzar en las hipótesis planteadas.

Agradecimientos: Al CONICET y a los evaluadores de Chungara.

\section{Referencias Citadas}

Aschero, C. 1983. Ensayo para una clasificación morfológica de artefactos líticos. Cátedra de Ergología y tecnología, Universidad de Buenos Aires. Manuscrito en posesión del autor.

- _ _ 1994. Reflexiones desde el Arcaico Tardío (6000-3000 AP). Rumitacana. Revista de Antropología 1 (1):13-17.

_ _ _ 2011. Holoceno medio en la Puna Argentina: Dos puntos de observación para la cultura material y una perspectiva regional. En Poblaciones y Ambientes en el Noroeste Argentino durante el Holoceno Medio, editado por M. Mondini, J. Martínez, H. Muscio y M. Marconetto, pp. 33-43. Universidad de Córdoba, Córdoba.

Aschero, C. y J. Martínez 2001. Técnicas de caza en Antofagasta de la Sierra, Puna Meridional Argentina. Relaciones de la Sociedad Argentina de Antropología XXVI: 215-241.

Boone, J. 1992. Competition, conflict and development of social hierarchies. En Evolutionary Ecology and Human Behavior, editado por E. Smith y B. Winterhalder, pp. 301-337. Hawthorne, N. Y. Aldine de Gruyter.

Bousman, B. 1993. Hunter gatherer adaptations, economic risk and tool design. Lithic Technology 18:59-86.

Boyd, R. y P. Richerson 1985. Culture and the Evolutionary Process. University of Chicago Press, Chicago.
Broughton, J. 1999. Resource Depression and Intensification During the Late Holocene, San Francisco Bay. University of California Press, Berkeley, Los Ángeles.

Cartajena, I., L. Núñez y M. Grosjean 2007. Camelid domestication on the western slope of the Puna de Atacama, northern Chile. Anthropozoologica 42:155-173.

Elkin, D. 1996. Arqueozoología de Quebrada Seca 3: Indicadores de Subsistencia Humana Temprana en la Puna Meridional Argentina. Tesis Doctoral. Universidad de Buenos Aires, Buenos Aires.

Egeland, C. 2003. Carcass processing intensity and cutmark creation: An experimental approach. Plains Anthropologist 48 (184):39-51.

Escola, P. 2002. Caza y pastoralismo: un reaseguro para la subsistencia. Relaciones de la Sociedad Argentina de Antropología XXVII: 233-245.

Fernández, J. 1983. Río Grande: Exploración de un centro precerámico en las altas montañas de la Puna de Jujuy (Argentina). Ampurias 45-46:54-83.

Fernández Distel, A. 1978. Nuevos hallazgos precerámicos en la región de Salinas Grandes, Puna de Jujuy Argentina. Revista del Instituto de Antropología tomo VI:15- 62. Universidad de Córdoba. 
Göbel, B. 2001. El ciclo anual de la producción pastoril en Huancar (Jujuy, Argentina), En El Uso de los Camélidos A Través del Tiempo, editado por G. Mengoni Goñalons, D. Olivera y H. Yacobaccio, pp. 91-115. Ediciones del tridente, Buenos Aires.

Hocsman, S. 2006. Producción lítica, Variabilidad y Cambio en Antofagasta de la Sierra - ca 5500-1500 AP-. Tesis de doctorado, Universidad de La Plata, La Plata.

Jones, G. y C. Beck 1992. Chronological Resolution in Distributional Archaeology. En Space, Time and Archaeological Landcapes, editado por J. Rossignol y L. Wandnider, pp. 167192. Interdisciplinary Contributions to Archaeology, Plenum Press, New York \& London.

Kelly, R. 1992. Mobility/sedentism: concepts, archaeological measures and effects. Annual Review of Anthropology 21:43-66.

López, G. 2009a. Arqueofaunas, osteometría y evidencia artefactual en Pastos Grandes, puna de Salta: secuencia de cambio a lo largo del Holoceno temprano, medio y tardío en el sitio Alero Cuevas. Intersecciones en Antropología 10:105-119.

_ _ _ 2009b. Diversidad arqueológica y cambio cultural en Pastos Grandes, Puna de Salta, a lo largo del Holoceno. Relaciones de la Sociedad Argentina de Antropología XXXIV:149-176.

_. _ _ 2012. Archaeological studies in the highlands of Salta, Northwestern Argentina, during Middle Holocene: The case of the Pocitos and Pastos Grandes Basins. Quaternary International 256:27-34

López, G., F. Coloca y J. Orsi 2012. Human occupations during the Middle Holocene and beginning of the Late Holocene the Pocitos Basin, Puna of Salta, Argentina: New research and Regional comparison. Quaternary International, en prensa.

López, G. y F. Restifo 2012. The Middle Holocene intensification and domestication of camelids in north Argentina, tracked by zooarchaeology and lithics. Antiquity 86:1041-1054.

Meadow, R. 1987. Techniques for comparing bone measurement data from small samples. Trabajo presentado en el Northeastern Faunal Analysis Conference. Connecticut.

Mengoni Goñalons, G. 1999. Cazadores de Guanacos de la Estepa Patagónica. Sociedad Argentina de Antropología. Colección de Tesis Doctorales.

Mengoni Goñalons, G. y H. Yacobaccio 2006. The domestication of South American camelids. A View from the South-Central Andes. En Documenting Domestication, New Genetics and Archaeological Paradigms, editado por M. Zeder, D. Bradley, E. Emshwiller y B Smith, pp. 228-243, University of California Press, Berkeley.

Mercuri, C. y M. Glascock 2011. Primeros datos sobre la procedencia de obsidiana de un sitio Formativo de Santa Rosa de los Pastos Grandes, Puna de Salta, Argentina. Revista Arqueología 17 , en prensa.

Moore, K. 1989. Hunting and the Origins of Herding in Peru. $\mathrm{Ph}$ dissertation, University of Michigan, Ann Arbor. University Microfilms, Ann Arbor.
Muscio, H. 2004. Dinámica Poblacional y Evolución Durante el Período Agroalfarero Temprano en el Valle de San Antonio de los Cobres, Puna de Salta, Argentina. Tesis Doctoral, Facultad de Filosofía y Letras, Universidad de Buenos Aires, Buenos Aires.

Nelson, M. 1991. The study of technological organization. Journal of Archaeological Method and Theory 3:57-100.

Núñez, L. 1992. Ocupación arcaica en la Puna de Atacama: secuencia, movilidad y cambio. En Prehistoria Sudamericana. Nuevas perspectivas, editado por B. Meggers, pp. 283-307. Taraxacum, Washington.

Núñez, L., M. Grosjean e I. Cartajena 2005. Ocupaciones Humanas y Paleoambientes en la Puna de Atacama. Universidad Católica del Norte-Taraxacum, San Pedro de Atacama.

Olivera, D. 2001. Sociedades Agropastoriles Tempranas: El Formativo Inferior del Noroeste Argentino. En Historia Argentina Prehispánica, editado por E. Berberián y A. Nielsen. Tomo 1, pp. 83-125. Editorial Brujas. Córdoba.

Olivera, D., P. Tchilinguirian y L. Grana 2004. Paleoambiente y arqueología en la Puna Meridional Argentina: Archivos, ambientales, escalas de análisis y registro arqueológico. Relaciones de la Sociedad Argentina de Antropología XXIX:229-247.

Ratto, N. 2003. Estrategias de Caza y Propiedades del Registro Arqueológico en la Puna de Chaschuil (Dpto. de Tinogasta, Catamarca, Argentina). Tesis de doctorado, Facultad de Filosofía y Letras, Universidad de Buenos Aires, Buenos Aires.

Schlanger, S. 1992. Recognizing persistent places en Anasazi settlement systems. En Space, Time and Archaeological Landcapes, editado por J. Rossignol y L. Wandnider, pp. 91-112. Plenum Press, New York.

Wheeler, J.C. 1998. Evolution and origin of the domesticated camelids. Alpaca Registry Journal 3:1-16.

Yacobaccio, H. 2001. Cazadores complejos y domesticación de camélidos. En El Uso de los Camélidos A Través del Tiempo, editado por G. Mengoni Goñalons, D. Olivera y H. Yacobaccio, pp. 261-281. Ediciones del tridente, Buenos Aires.

Yacobaccio, H., D. Elkin y D. Olivera 1994 ¿El fin de los sociedades cazadoras? El proceso de domesticación animal en los Andes centro-sur. En Arqueología de Cazadores-Recolectores. Límites, Casos y Aperturas. Arqueología Contemporánea 5. Edición Especial, compilado por J. Lanata y L.A. Borrero, pp. 23-32. Programa de Estudios Prehistóricos, Buenos Aires.

Yacobaccio, H., P. Escola, F. Pereyra, M. Lazzari y M.D. Glascock 2004. Quest for ancient routes: obsidian sourcing research in Northwestern Argentina. Journal of Archaeological Science 31:193-204.

Yacobaccio, H. y M. Morales 2005. Mid-Holocene environment and human occupation of the Puna (Susques, Argentina). Quaternary International 132:5-14.

Yacobaccio, H. y B. Vilá 2002. Condiciones, mecanismos y consecuencias de la domesticación de los camélidos. Estudios Sociales del NOA 5:4-27. Tilcara. 